\title{
PROJETOS DE ESCOLARIZAÇÃO E INGRESSO \\ DE ESTUDANTES NEGROS NA UNIVERSIDADE EM CONTEXTO DE AÇÕES AFIRMATIVAS
}

\author{
ANDREA BAYERL MONGIM ${ }^{1}$
}

\section{Resumo}

Neste artigo busco analisar projetos de escolarização construídos por discentes negros, oriundos de famílias de baixa renda, que ingressaram na universidade, mediante sistema de cotas. O implemento de ações afirmativas para o ingresso no ensino superior tem assumido fundamental importância para a efetivação de tais projetos. No entanto, além das dificuldades de ordem material, são significativos os desafios de ordem simbólica. Tem-se observado concepções e práticas discriminatórias por parte de grupos, agentes institucionais ou nas relações interpessoais. Conclui-se que as concepções de justiça subjacentes às políticas de ação afirmativa, propulsoras da objetivação do projeto de ingresso na universidade, não são observadas no que se refere à permanência e à conclusão do curso superior.

Palavras-chave: Estudantes negros. Ações afirmativas. Ensino superior.

PROJECTS FOR SCHOOLING AND ENTRYING OF BLACK STUDENTS IN THE COLLEGE IN CONTEXT OF AFFIRMATIVE ACTIONS

\begin{abstract}
In this article I analyze education projects built by black students and considered coming from low-income families who entered in college by quota reservation system. The implement of affirmative action for admission to higher education has assumed of fundamental importance for the
\end{abstract}

1 Doutora em Antropologia pela Universidade Federal Fluminense (UFF). Realiza pós-doutorado em Ciências Sociais na Universidade Federal do Espírito Santo (UFES) e é pesquisadora do Núcleo de Estudos Afro-Brasileiros da mesma instituição. 
realization of such projects. However, beyond the difficulties of a material nature, they are significant challenges of symbolic order. Discriminatory conceptions and practices have been observed by groups, institutional agents or interpersonal relations. It is concluded that the conceptions of justice that underlie affirmative action policies, propelling the objectivation of the university admission project, are not observed with regard to the permanence and completion of the university course.

Keywords: Black students. Affirmative action. Higher education.

\section{POYECTOS DE ESCOLARIZACIÓN Y ADMISIÓN DE ESTUDIANTES NEGROS EN LA UNIVERSITAD EN CONTEXTO DE LA ACCIÓN AFIRMATIVA}

\section{Resumen}

En este artículo se analizan los proyectos educativos construidos por los estudiantes negros, provenientes de familias de bajos ingresos, que entraron en la universidad, através del sistema de cuotas. La acción afirmativa para la admisión a la educación superior ha adquirido una importancia fundamental para la realización de este tipo de proyectos. Sin embargo, más allá de las dificultades de orden material, son significativos los retos de orden simbólico. Se ha observado concepciones y prácticas discriminatorias de los grupos, agentes institucionales o en las relaciones interpersonales. Se concluye que las concepciones de la justicia que se basan las políticas de acción afirmativa, la cosificación de propulsar el proyecto billete en la universidad, no se observaron con respecto a la permanencia y la finalización de la educación superior.

\section{Introdução}

Neste artigo, analiso resultados parciais de uma pesquisa etnográfica que venho desenvolvendo com estudantes que ingressaram na Universidade Federal do Espírito Santo (UFES) mediante sistema de reserva de vagas. Para efeito deste texto, considero experiências de discentes autoidentificados como pardos e pretos. ${ }^{2}$

2 Passarei a considerar, a partir deste ponto, pretos e pardos como negros, conforme nomenclatura que vem sendo adotada, como observa Gomes (2011), pelo Movimento Negro e por intelectuais que, ao analisarem a situação do negro brasileiro, agregam as categorias raciais "preto" e "pardo", entendendo-as como expressão do conjunto da população negra no Brasil. 
Tal investigação incide sob um contexto em que o processo de ampliação das oportunidades de acesso ao ensino superior, no Brasil, tem se constituído em problemática política, merecendo destaque a implementação de políticas de ação afirmativa, expressas em programas de reserva de vagas em instituições de ensino superior (IES) públicas e de bolsas em IES privadas. Tomamos como base a definição de ações afirmativas como

Políticas e mecanismos de inclusão concebidos por entidades públicas, privadas e por órgãos dotados de competência jurisdicional, com vistas à concretização de um objetivo constitucional universalmente reconhecido - o da efetiva igualdade de oportunidades a que todos os seres humanos têm Direito (GOMES, 2001, p. 40).

Vale ressaltar que, no Brasil, os recentes programas de ações afirmativas têm sido implantados como resultado de expressivas lutas sociais, cujos principais protagonistas são integrantes de diferentes núcleos do Movimento Negro. Conforme destacam Paula e Heringer (2009), a Conferência Mundial contra o Racismo, Discriminação Racial, Xenofobia e Intolerâncias Correlatas, convocada pela ONU e realizada em Durban, África do Sul, em 2001, constitui-se em um dos marcos históricos que embasam as reivindicações do Movimento Negro contemporâneo e a implementação de políticas de ação afirmativa. Ademais, conforme destacam autores como Oliveira (2012) e Gomes (2011), o direito à educação sempre atraiu a atenção de agentes afiliados ao Movimento Negro, tornando-se forte bandeira de luta ainda no século XX.

O designado processo de inclusão no ensino superior vem assumindo contornos polêmicos e instituindo um acalorado debate, tanto no espaço público quanto no campo acadêmico, como demonstram, entre outros, Heringer e Ferreira (2009). Apesar de as chamadas ações afirmativas não se restringirem à reserva de cotas para ingresso de negros no ensino superior, o debate se constitui, em um primeiro momento, tanto na recente produção acadêmica ${ }^{3}$ quanto nas manifestações públicas, reacendendo a polêmica questão racial no Brasil.

Produções acadêmicas relativas a esse contexto têm sido constituídas, em grande parte dos casos, por pesquisas de caráter documental e bibliográfico, secundarizando análises que dizem mais diretamente respeito às concepções, práticas e atributos sociais dos atores envolvidos diretamente no processo. Atenta

3 Muitos trabalhos acadêmicos produzidos recentemente sobre o assunto expressam claramente a posição política dos pesquisadores, contrários ou favoráveis às cotas raciais. 
a essa lacuna, fiz um primeiro investimento de pesquisa analisando percursos sociais de estudantes universitários que ingressaram em uma IES não pública na condição de beneficiários do ProUni (MONGIM, 2010). No presente estudo, procuro analisar projetos de escolarização construídos ao longo dos itinerários sociais de estudantes negros e oriundos de famílias consideradas de baixa renda que ingressaram em uma instituição de ensino superior mediante sistema de reserva de vagas.

Assumindo uma proposta de pesquisa etnográfica, privilegiei como lócus de referência, para o trabalho de campo, o universo institucional onde, cotidianamente, compartilham experiências estudantes matriculados nos cursos de Ciências Sociais, de Medicina e de Direito da Universidade Federal do Espírito Santo. O trabalho de observação vem ocorrendo desde o segundo semestre de 2011, quando iniciei atividades como professora visitante junto ao Departamento de Ciências Sociais da mencionada IES. Fiz opção pela realização de entrevistas do tipo "relato de vida", conforme perspectiva proposta pelo sociólogo Bertaux (1997). Considerando que o termo "história de vida" apresenta-se de forma pouco conveniente, uma vez que não distingue a história vivida por uma pessoa e o relato feito por ela, Bertaux (1997) elege por opção epistemológica "relatos de vida" como unidade de análise. $\mathrm{O}$ autor assim o faz compreendendo que o termo se apresenta de forma epistemologicamente mais adequada, uma vez que um relato pessoal somente corresponde a uma aproximação da história objetivamente ou subjetivamente vivida por alguém. Portanto, ao optar pela reconstituição da história de vida de alguém exclusivamente através do seu próprio relato, o pesquisador somente tem a ilusão de tê-lo feito.

De acordo com Bertaux (1997, p. 6), "o relato de vida resulta de uma forma particular de entrevista, uma entrevista narrativa, ao curso da qual um pesquisador solicita a uma pessoa, denominada sujeito, a contar toda ou parte de sua experiência vivida". O sociólogo diferencia "mundo social" de "categorias de situação", demonstrando que estas não necessariamente são partes constituintes do primeiro. Citando como exemplos de categorias de situação mães que criam seus filhos sozinhas, pais divorciados, toxicômanos e estrangeiros em situação irregular, Bertaux enfatiza a diversidade de contextos. Tais situações, em sua perspectiva, só configuram "situações sociais em comum" na medida em que engendram "regras e lógicas de ação que apresentam pontos em comum: é percebida através de esquemas coletivos e, eventualmente, tratada por uma mesma instituição" (BERTAUX, 1997, p. 15). 
No caso desta pesquisa, defino como "categoria de situação" estudantes universitários negros e oriundos de famílias consideradas de baixa renda que, entre o primeiro semestre do ano de 2008 e o segundo do ano de 2015, ingressaram nos cursos de Ciências Sociais, Medicina e Direito da Universidade Federal do Espírito Santo mediante programa de reserva de cotas. Observo que, na primeira fase da pesquisa, fiz uso de métodos e técnicas de coleta de dados quantitativos. Isso porque também visava analisar quantitativamente o ingresso de estudantes negros na UFES no período posterior à implantação do primeiro sistema de cotas adotado pela Instituição. Nesse momento, realizei uma busca quantitativa com base em dados coletados e previamente organizados pela Comissão Coordenadora do Vestibular a partir de questionário respondido pelos estudantes no momento que se inscreveram para o processo seletivo.

Este artigo encontra-se organizado da seguinte forma: na primeira seção, descrevo sucintamente o processo de implementação dos sistemas de reserva de vagas na UFES e analiso os efeitos destes sistemas no que se refere ao ingresso de estudantes negros na instituição. Na seção seguinte, analiso projetos de escolarização dos estudantes considerados nesta pesquisa, destacando os efeitos do sistema de reserva de vagas para ingresso no ensino superior. Na terceira seção, discuto os dilemas e tensões vivenciados pelos discentes no processo de inserção na universidade. Na quarta seção, apresento as considerações finais.

\section{O sistema de reserva de vagas e o ingresso de estudantes negros na Universidade Federal do Espírito Santo}

Na UFES, a partir de 2008, foi adotado um sistema próprio de reserva de vagas com base em critérios sociais. O sistema aliava renda familiar à situação de egresso de escola pública. O modelo adotado estabeleceu a reserva de $40 \%$ do total de vagas de cada curso para jovens cuja situação concordasse com os critérios, sendo possível o aumento para $45 \%$ e $50 \%$ naqueles cursos onde a oferta de vagas fosse ampliada. A reserva de vagas contemplava estudantes oriundos de famílias com renda inferior a sete salários mínimos e que tivessem cursado pelo menos quatro anos das séries do ensino fundamental e todo o ensino médio em escola pública.

Em artigo onde discuto os efeitos de tal sistema no processo de diversificação dos atributos sociais e econômicos dos estudantes ingressantes na mencionada 
instituição (MONGIM, 2012), procurei demonstrar que, no que se refere à autoidentificação quanto à raça/cor, só se observou aumento mais expressivo de estudantes negros nos cursos considerados de menor prestígio social e concorrência.

A partir do vestibular de 2012, obedecendo ao que preconiza a Lei Federal $\mathrm{n}^{\circ} 12.711 / 2012$, a UFES passou a considerar, imediatamente após a aprovação desta, reserva de $50 \%$ das vagas, aliando critérios sociais e étnico-raciais. Com essa alteração, o aumento de ingressantes cotistas negros passou a ser mais significativo. Na maior parte dos cursos, discentes autoidentificados como pretos e pardos passaram a somar mais da metade dos ingressantes. No entanto, em cursos como Medicina e Direito, os estudantes autoidentificados como brancos permaneceram constituindo maioria entre os ingressantes.

Vale lembrar que, no quadro populacional do Estado do Espírito Santo, de acordo com dados do último censo do IBGE (2010), os autoidentificados como pardos e pretos constituem maioria, somando 56, $9 \%$. A UFES até então não havia aderido ao SISU, ${ }^{4}$ recebendo, assim, estudantes, principalmente, do próprio estado.

Se o sistema de cotas tem contribuído para aumentar, ainda que de forma limitada, a inclusão de estudantes negros na universidade, o processo de ingresso e permanência tem ocorrido em meio a muitos dilemas e constrangimentos. Como será discutido posteriormente, esses estudantes têm sistematicamente convivido com práticas representativas de discriminação e racismo, seja por parte de seus pares, seja por parte da própria instituição.

\section{Projetos de escolarização, acesso ao ensino superior e ações afirmativas}

Os estudantes em questão vêm construindo percursos escolares singulares, se comparados aos seus pais e irmãos. Filhos de trabalhadores dedicados a atividades não-qualificadas, próprias ao mercado de trabalho urbano, eles representam, em geral, a primeira experiência familiar de ingresso no curso superior. O projeto de ingressar na universidade é construído, na maior parte dos casos, de forma não naturalizada, ao longo dos percursos analisados, ocorrendo, mais

4 Sistema de Seleção Unificada desenvolvido pelo Ministério da Educação para selecionar candidatos às vagas das instituições públicas de ensino superior que utilizarão a nota do Enem como única fase de seu processo seletivo. 
especificamente, no processo que Berger e Luckman (2001) denominaram "socialização secundária", que ocorre a partir da interação com diferenciados "agentes de mediação social” (NEVES, 2008), posicionados, na maior parte das vezes, em quadros institucionais que ultrapassam os limites das redes de relações da família nuclear. A esse respeito, Miriam, estudante do curso de Ciências Socais faz a seguinte consideração:

Eu não tinha aquela ideia que ia terminar o segundo grau e fazer cursinho pra entrar na UFES. Eu tinha em mente, desde cedo, que deveria terminar o segundo grau e trabalhar (informação verbal).

Pode-se observar experiência diferenciada entre parte dos estudantes do curso de Medicina e entre os mais jovens do curso de Direito e de Ciências Sociais. Entre alguns estudantes do curso de Medicina, tornar-se médico(a) foi concebido como um Isso ocorre, sobretudo, a partir da própria experiência dos estudantes em contato permanente com profissionais da área devido à necessidade de cuidados com a própria saúde ou de algum familiar, conforme pode ser observado no relato a seguir, de Ana, estudante do primeiro período do curso.

Comecei a pensar em Medicina desde nova; na quinta, sexta série já tinha [isso] em mente, por ter a minha irmã mais velha, com problemas, com retardo mental. Meu irmão também teve um acidente, quase amputou a perna, minha mãe tem pressão alta, [está] sempre passando mal. Então, [eu] estava sempre em contato, desde cedo, acompanhando no hospital, vendo a correria dos enfermeiros, médicos, assistindo um pouco de televisão. $\mathrm{Me}$ encantei pela Medicina, [tornou-se] um sonho (informação verbal).

Entretanto, se há diferenciação no que se refere à construção do projeto, sua objetivação ocorre, para estudantes dos dois cursos considerados, principalmente, a partir das interações com mediadores sociais, posicionados nas diferentes redes de sociabilidade constituídas ao longo dos itinerários em questão. Os referidos agentes podem ser mediadores personalizados como membros da família extensa, professores e colegas de trabalho, mas também, muitas vezes, mediadores do tipo formal-legal. Estes estão geralmente posicionados nas organizações e nos programas governamentais, como é o caso dos afiliados a projetos e programas não governamentais, como aqueles que atuam em cursos do tipo pré-vestibular para negros e carentes (PVNC). 
Ainda que por diferentes categorias de análise, outros trabalhos também têm demonstrado as relações que estudantes oriundos de famílias de baixa renda estabelecem com mediadores personalizados ou com aqueles do tipo formal-legal no processo de mudança para a posição de estudantes universitários. No estudo de Teixeira (2003), a autora teve a intenção de contribuir para o estudo das relações raciais através da análise dos percursos de estudantes e professores negros de uma IES pública, a Universidade Federal Fluminense (UFF), localizada no Rio de Janeiro. Constatando que o perfil dos seus entrevistados se caracteriza por "indivíduos de origem social mais baixa, que frequentaram escolas de primeiro e segundo graus de ensino deficiente e que, por alguma razão, conseguem ascender ao ensino superior, considerado de bom nível" (TEIXEIRA, 2003, p. 186), a autora demonstrou que a capacidade de estabelecer uma rede de solidariedade e de ajuda foi o fator determinante das trajetórias em ascensão. Outros estudos também o fizeram mesmo não se referindo a estudantes negros; refiro-me àqueles desenvolvidos por Mongim (2010), Dauster (2004), Souza e Silva (1999) e Honorato (2005). Em estudo mencionado anteriormente, analisei percursos sociais de estudantes beneficiários do Programa Universidade para Todos (Prouni) que ingressaram em IES privada (MONGIM, 2010). Por sua vez, Dauster (2004) analisou a entrada e a permanência de estudantes beneficiados por uma bolsa social (institucional) de uma universidade não pública. Honorato (2005), assumindo como propósito discutir as "estratégias coletivas em torno da formação universitária", analisou os percursos de estudantes que ingressaram na Universidade Federal do Rio de Janeiro (UFRJ) a partir da inserção nos cursos PVNC. Souza e Silva (1999) buscou analisar percursos escolares bem sucedidos, objetivados por moradores das comunidades da Maré - um dos maiores complexos de favelas do Rio de Janeiro - rumo ao curso superior.

Na maioria dos casos, tanto nos mencionados estudos, quanto nos que aqui analiso, as relações estabelecidas com agentes institucionais de mediação social, afiliados a movimentos sociais, com destaque para cursos do tipo pré-vestibular para negros e carentes, foi essencial. No percurso de Sonia, por exemplo, a preparação para o vestibular de Medicina só foi possível através da dedicação aos estudos em dois cursos do tipo pré-vestibular alternativos:

Fiz os dois ao mesmo tempo, o PUPT e o Dandara. Isso a semana toda. No sábado, tinha de manhã também. Às vezes, coincidiam os dois. Faltava um, ia no outro. À tarde fazia inglês no Idiomas, que é um projeto também do estado. No domingo de manhã, tinha também um cursinho, na igreja, só de 
discursiva de biologia e química. Eu também participava. Então era assim minha rotina (informação verbal).

Também há, na maior parte dos casos considerados, o explícito reconhecimento do quanto o sistema de cotas constituiu-se como fator fundamental para a objetivação do projeto de ingresso na universidade, possibilidade significativamente valorizada como grande alternativa mediante expectativa de projeção de uma vida melhor. Alguns dos estudantes afirmam que fariam o vestibular mesmo não havendo a implantação do sistema, mas reconhecem o estímulo. No caso de Miriam, a possibilidade de ingresso a partir da reserva de vagas foi fundamental, como parece sugerir seu relato:

Como eu me enquadrava no perfil, eu disse: "as cotas vão me ajudar", porque seria difícil disputar com alguém que tinha estudado o tempo todo em escola particular, pela questão econômica que tinha. Com certeza, [competindo] com todo mundo eu não ia ter chance, aí eu fiz e nem acreditei quando passei (informação verbal).

Pelas experiências relatadas por esses discentes, é possível perceber que, tanto a organização dos cursos do tipo PVNC como os programas de reserva de cotas para ingresso nas universidades federais, aqui concebidos como modalidades de ação afirmativa, colocam-se como fundamentais para alavancar o acesso de estudantes negros no ensino superior.

\section{Os dilemas e desafios do ingresso na universidade pelo sistema de cotas}

Para os discentes em questão, dos cursos considerados, a inserção em um novo universo de significados traz à tona sentimentos e sentidos diversos. Em geral, eles apontam dificuldades de ordem material, mas também ressaltam os desafios diante da percepção de que a vida transita entre dois mundos, em universos simbólicos diferentes. Por isso, ao mesmo tempo em que o acesso à universidade é comemorado e concebido como grande possibilidade de a percepção da alteridade pode se apresentar como um desafio. Ao relatar sua experiência ao ingressar na universidade, Solange, estudante do primeiro período do curso de Direito, fez a seguinte declaração: 
Foi muito ruim, foi bem decepcionante no início, porque eu achava que seria como minha turma no IFES [Instituto Federal do Espírito Santo], que era muito unida, tipo família mesmo, todo mundo muito, muito unido. Claro que tinham desavenças também. Só que aqui, na UFES, no curso de Direito, parece uma competição, parece que tem pessoas ali que usam a cabeça das outras como um degrau para subir. Eu brinco com a mamãe que eu fui jogada em um ninho de cobras sem ter conhecimento do que eu estava fazendo. Começou a ser muito frustrante para mim, porque você vê que é um Direito focado para uma parte que é minoria. Eu vim da periferia, eu sei que o que eles falam é lindo, mas não acontece para a maior parte da população. Eu sou apaixonada [pelo] meu curso, mas não sei se vou consegui me habituar com as pessoas, com o meio, que é uma coisa de um competindo com o outro, um contra o outro - não necessariamente com todo mundo, tanto que tem pessoas na sala [com] que[m] eu converso, só que tem pessoas que não faço questão, porque passam na rua e fingem que não me conhecem (informação verbal).

O sentido do pertencimento passa a constituir-se, assim, por muitas tensões e constrangimentos. Nesses termos, o processo de mobilidade assume significados expressivos dos prazeres da conquista, mas também tradutores de dores e sofrimentos.

Apesar de, em alguns casos, os estudantes tenderem, por efeitos de posição, secundarizar as dificuldades presentes no processo de pertencimento a um novo espaço simbólico, são significativamente evidentes as práticas representativas de estigmatizacão, discriminação e exclusão nas relações interpessoais por parte de grupos ou agentes institucionais. Tais práticas são mais evidentes entre os estudantes inscritos nos curso de Direito e de Medicina, porém, não deixam de ser observadas também entre os do curso de Ciências Sociais.

Ao se referir, por exemplo, às relações estabelecidas entre estudantes cotistas e não cotistas do curso de Medicina, Sandro, estudante que, no momento da entrevista, cursava o sexto período deste, fez as seguintes considerações:

No início, no primeiro e [no] segundo períodos, ainda tem desdém, diferencial. Eles não se agregam muito. Fica aquela divisão. Uma ala é cotista, outra não cotista. Então, geralmente, fica aquele pessoal que veio de determinada escola particular, de uma mesma turma, de curso integral que pagava 1500 reais, sei lá quanto, que já se conhecia, se unem e fazem ali um círculo de amizade. Os demais geralmente são mais simples, mais acanhados, menos favorecidos; em questão de imagem, de estética, são os mais simplesinhos. É meio como que tivesse caracterizando assim: aquele ali é pobre, aquele 
ali é o cotista, mesmo já sabendo pela lista que sai, né? Quando chega o terceiro, quarto período em diante, já começa a dar aquela homogeneizada, as matérias começam a ser completamente novas para todas as turmas e os cotistas começam a se manter no mesmo nível que os não cotistas, tipo assim, disputando o primeiro, o segundo lugar em termos de notas. Começa a homogeneizar também [por] ter a questão da maturidade. No início, os nãos cotistas vêm cheios de preconceito. Percebo amizades entre cotista $\mathrm{e}$ não cotistas, mas não no início, só bem depois. Pelo menos foi assim na minha turma (informação verbal).

Outra aluna fez o seguinte relato a respeito das relações entre os estudantes:

A gente não tem tanto essa discriminação não, "só conversa com você que não é cotista”, conversa normal, tem amizade saudável. Acontece que, às vezes, algumas discussões tocam no assunto, [...] mas, no cotidiano, conversa normal. É muito tranquilo, pelo menos a minha turma, mas já ouvi casos, relatos de que, em determinadas turmas, as pessoas não conversam umas com as outras porque tem a mágoa mesmo, "ah, tentei cinco anos, seis anos e você de primeira passou" e tal... Então, realmente, mas isso vai de turma pra turma. Às vezes estudaram juntos no pré-vestibular e, então, formam grupinhos mesmo (informação verbal).

Um dos estudantes entrevistados, Jonas, inscrito no segundo período do curso de Direito, relatou que, a princípio, não se dava conta de atitudes preconceituosas em relação aos cotistas e, em particular, aos cotistas negros. Ele buscava, inclusive, integrar-se aos grupos de estudantes não cotistas. Um episódio, no entanto, o fez perceber situação inversa. Segundo seu relato, ele se encontrava conversando informalmente com estudantes do mencionado grupo, quando, ao comentarem a respeito do furto de uma bicicleta nas dependências da universidade, um dos estudantes afirmou que Os demais o apoiaram em sua opinião. Ao relatar tal fato, Jonas não conseguiu esconder o quanto se sentiu ofendido, tomando, posteriormente, a decisão de se afastar daquele grupo.

Ainda em relação a estudantes do curso de Direito, foi possível identificar, nos relatos, a formação de um grupo denominado "Direito Vip". A esse respeito, Santos (2014, p. 311), em estudo onde discute a relação raça/classe no processo de constituição do sistema de cotas na UFES, faz a seguinte consideração, com base nos relatos de seus entrevistados:

O "Direito Vip" foi criado "secretamente" no Facebook por alunos de classe média e ex-estudantes de escolas privadas de grande prestígio e onerosas 
do Espírito Santo, como Darwin e Leonardo da Vinci. O objetivo de seus proponentes era se distinguir de cotistas e pobres. Para Marta, muitos dos que não fazem parte do "Direito Vip" ficam isolados, apesar de ter professores e alunos do curso que lutam contra isso ou por uma universidade menos elitista.

Tais práticas nos remetem às reflexões de Elias e Scotson (2000) a respeito dos "estabelecidos" e os . Essas categorias, de caráter relacional, são discutidas pelos mencionados autores em uma etnografia das relações de poder na comunidade de Winston Parva (nome fictício), próxima de Leicester, Inglaterra, localidade marcada pela existência de um grupo de moradores antigos da "aldeia", os "estabelecidos", que se colocavam como pessoas de "valor humano mais elevado" do que o dos moradores do "loteamento", construído em época mais recente, os estigmatizados pelos primeiros. As análises dos autores apontam ser graças a um maior potencial de coesão que os antigos residentes de Winston Parva, os "estabelecidos", conseguiram reservar para as pessoas de seu tipo os cargos importantes das organizações locais, como o conselho, a escola ou o clube, e deles excluir firmemente os moradores de outras áreas, aos quais, como grupo, faltava coesão. A exclusão e a estigmatização dos pelo grupo estabelecido constituíam-se em armas poderosas para que este preservasse sua identidade e afirmasse sua superioridade, mantendo os outros firmemente em seu lugar.

No caso em análise, ainda que, como Dauster (2004), não considero produtivo radicalizar a analogia proposta, as relações entre cotistas e não cotistas, especialmente os negros de baixa renda, tendem a ocorrer de forma tensa e desigual, tal como entre os estabelecidos e analisados por Elias e Scotson (2000). Os que discriminam parecem também compartilhar da percepção de fazerem parte de algum grupo de "valor humano mais elevado", percepção esta que parece assentada em relações sociais estabelecidas para além dos muros da faculdade, amparadas em um sistema social que se estrutura de forma hierárquica, excludente e racista, conforme destacam autores como Da Matta (1987), Munanga (1996), entre outros.

As relações entre os diferentes agentes vão, aos poucos, revelando que, se existe um "valor humano mais elevado", ele se constrói pautado num sistema meritocrático, que privilegia o alcance de resultados acadêmicos satisfatórios, demonstrados nas boas notas e em atributos como a desenvoltura para se expressar oralmente e a articulação de argumentos bem fundamentados nos debates. Assim, os estudantes cotistas e, ao que parece, parte dos não cotistas, tendem a perceber 
no bom desempenho acadêmico os atributos necessários a uma posição de reconhecimento, tanto por parte do outro como de sua própria, como alguém qualificado e de valor.

\section{Práticas institucionais representativas de discriminação e estigmatização}

No processo que analisamos, é também fundamental considerar práticas institucionais representativas de processos de discriminação, exclusão e estigmatização do outro. Algumas situações relatadas pelos estudantes e outras que também pude observar são significativas. Entre os discentes do curso de Medicina, alguns entrevistados referiram-se, de forma bastante crítica, à maneira como a instituição dividiu uma turma para aulas em laboratório de uma disciplina ofertada no primeiro semestre. Segundo relatos, a divisão foi feita separando estudantes cotistas de não cotistas. Em pesquisa já mencionada, Santos (2014) constatou que divisão semelhante aconteceu com turmas dos cursos de Arquitetura e Urbanismo. Como também pude observar, Santos (2015, p. 307) ressalta que "a reação dos alunos cotistas diante da divisão de turmas era um misto de indignação, consentimento e resignação".

Entre os estudantes do curso de Ciências Sociais, um professor do Departamento de Economia, em um debate ocorrido em sala de aula, declarou de forma bastante explícita sua posição discriminatória em relação aos estudantes cotistas, de modo geral e, em particular, aos cotistas negros. Segundo relatos dos estudantes presentes no debate, tal professor afirmou categoricamente que os cotistas baixam o nível do ensino da universidade, dizendo que, se tivesse que escolher entre um médico (ou advogado) branco e um médico (ou advogado) negro, escolheria o branco ${ }^{5}$ por ter certeza da maior competência dos profissionais desta cor/raça.

Ao final de uma palestra que proferi em uma turma do curso de Serviço Social, alguns dos estudantes me chamaram para observar um cartaz pichado com a seguinte frase: "Também tenho o direito de não concordar com as merdas

5 Além dos relatos dos estudantes, o caso ganhou forte repercussão, sendo amplamente divulgado nas redes sociais e na imprensa, conforme pode ser observado em reportagem publicada pelo jornal Folha de São Paulo, em 07 de novembro de 2014, intitulada "Professor do ES pede desculpas por declaração considerada racista" (COISSI, 2014). 
que cotistas escreve. Professor Malaguti ${ }^{6}$ para reitor. Fora cotistas!". Tal declaração deixa ainda mais evidente que o docente mencionado parece representar práticas e concepções discriminatórias a respeito dos cotistas compartilhadas por outros agentes e grupos presentes na instituição em foco.

Por fim, vale ainda relatar outra prática institucional semelhante às que têm sido consideradas até o momento. No processo de matrículas para o primeiro semestre de 2015, foi feita uma divisão, por parte do setor institucional responsável, entre estudantes cotistas e não cotistas. Os estudantes que ingressaram pelo sistema de cotas, do grupo de menor renda, tiveram que fazer matrícula em dia diferente dos demais. A instituição justificou tal atitude com base na necessidade de estes estudantes apresentarem documentação comprobatória de renda. A esse respeito, vale considerar que o momento da matrícula constitui, para os estudantes, um momento importante de inclusão na universidade, pois é quando os estudantes do segundo período de cada curso organizam diferentes rituais para a recepção dos calouros. Tendo que fazer matrícula em dias separados, a grande maioria dos estudantes cotistas foi apartada do processo, configurando uma evidente exclusão logo nos primeiros contatos com o novo e desconhecido universo simbólico.

\section{Considerações finais}

Conforme busquei demonstrar ao longo deste artigo, o implemento de ações afirmativas para ingresso no ensino superior, seja na modalidade de reserva de cotas ou de cursos do tipo pré-vestibular para negros e carentes, tem se constituído como de fundamental importância para a efetivação de projetos de escolarização de estudantes negros em nível superior. Tal processo parece evidenciar o propósito das políticas de ação afirmativa, pautadas por concepções que concebem a justiça como resultante da distribuição de riquezas aliada a processos de reconhecimento cultural, conforme aponta Fraser (2002). No entanto, como visto, o processo de ingresso e de permanência na universidade tem sido perpassado por concepções e por práticas que se colocam na contramão de tais propósitos. Se há, muitas vezes, por parte dos estudantes, dificuldades de ordem financeira (nem sempre superadas com os programas de assistência estudantil),

6 Referência feita ao professor acusado de declaração racista. 
são também amplos e significativos os desafios de ordem simbólica. As relações que se estabelecem no processo de ingresso e de permanência na universidade, sejam personalizadas ou por parte de grupos e agentes institucionais, são evidentemente contrárias às concepções de justiça que ancoram a formulação de políticas de ação afirmativa. Se há consenso em torno da necessidade de que as condições materiais de permanência sejam asseguradas aos estudantes, a importância do investimento sistemático no combate ao racismo e a toda e qualquer forma de exclusão não pode ser secundarizada. Frente a tais processos, parte dos estudantes têm se organizado em coletivos imbuídos destes propósitos. Muitos, porém, convivem com a constante sensação de serem, como destaca Santos (2014), intrusos buscando se situar em espaço não autorizado ou, nos termos discutidos por Bourdieu (1990), um "excluído no interior".

Por essas considerações, os agentes sociais preocupados com a construção de instituições universitárias efetivamente democráticas estão diante do desafio da necessária implantação, de maneira coletiva e participativa, de programas de permanência também voltados para a valorização da diversidade e para a inclusão, em amplo sentido, dos grupos historicamente excluídos das universidades.

\section{Referências}

BERGER, Peter Ludwig; LUCKMAN, Thomas. 22. ed. Petrópolis: Vozes, 2001.

BERTAUX, Daniel. perspectives ethnosociologiques. Paris: Nathan, 1997.

BOURDIEU, Pierre. Os excluídos do interior. In: NOGUEIRA, Maria Alice; CATANI, Afrânio (Org.). Petrópolis: Vozes, 1990. p. 218-227.

COISSI, Juliana. Professor do Espírito Santo pede desculpas por declaração considerada racista. São Paulo, 11 nov. 2014. Caderno Cotidiano. Disponível em: <http:// www1.folha.uol.com.br/cotidiano/2014/11/1545018-professor-do-es-pede-desculpas-por-declaracao-considerada-racista.shtml>. Acesso em: 26 out. 2015.

DA MATTA, Roberto. Digressão: a fábula das três raças, ou o problema do racismo à brasileira. In: DA MATTA, R. Uma introdução à antropologia social. Rio de Janeiro: Rocco, 1987. p. 58-85. 
DAUSTER, Tania. "Uma revolução silenciosa": notas sobre o ingresso de setores de baixa renda na universidade. In: CONGRESSO LUSO-AFRO-BRASILEIRO DE CIÊNCIAS SOCIAIS, 8., 2004, Coimbra. Disponível em: <www.ces.uc.pt/lab2004/pdfs/TaniaDauster. pdf>. Acesso em: 30 mar. 2013.

ELIAS, Norbert; SCOTSON, John L. Rio de Janeiro: Jorge Zahar, 2000.

FRASER, Nancy. A justiça social na globalização: redistribuição, reconhecimento e participação, n. 63, p. 7-20, out. 2002.

GOMES, Nilma Lino. Diversidade étnico-racial, inclusão e equidade na educação brasileira: desafios, políticas e práticas, v. 27, n. 1, 2011

HERINGER, Rosana; FERREIRA, Renato. Análise das principais políticas de inclusão de estudantes negros no ensino superior no Brasil no período 2001-2008. In: PAULA, Marilene de; HERINGER, Rosana (Org.). Estado e sociedade na superação das desigualdades raciais no Brasil. Rio de Janeiro: Heinrich Böll Stiftung, 2009. p. 137-196.

HONORATO, Gabriela. S. Estratégias coletivas em torno da formação universitária: status, igualdade e mobilidade entre desfavorecidos. Dissertação (mestrado em Sociologia). Universidade Federal do Rio de Janeiro-Instituto de Filosofia e Ciências Sociais, Rio de Janeiro, 2005.

INSTITUTO BRASILEIRO DE GEOGRAFIA E ESTATÍSTICA. Censo demográfico. Rio de Janeiro, IBGE, 2010.

MONGIM, Andréa Bayer. v. 1, n. 1, jan./jun. 2012

MONGIM, Andréa Bayer. percursos sociais de estudantes beneficiários do Prouni. 2010. 176 f. Tese (Doutorado em Antropologia) - Universidade Federal Fluminense, Niterói, 2010.

MUNANGA, Kabengele. O anti-racismo no Brasil. In: MUNANGA, Kabengele (Org.). São Paulo: Edusp: Estação Ciência, 1996. p. 79-94.

NEVES, Delma Pessanha (Org). Mediação social e mediadores políticos. In: NEVES, Delma Pessanha. Porto Alegre: Editora da UFRGS, 2008. p. 21-44.

OLIVEIRA, Luiz Fernandes. desafios políticos, epistemológicos e identitários para a formação dos professores de História. Rio de Janeiro: Imperial Novo Milênio, 2012.

PAULA, Marilene de; HERINGER, Rosana. (Org.). Estado e sociedade na superação das desigualdades raciais no Brasil. Rio de Janeiro: Heinrich Böll Stiftung, 2009. p. 137-196. 
SANTOS, Sérgio Pereira dos. As relações de raça e classe na implementação das cotas sociais no processo seletivo para cursos de graduação da UFES - 2006-2012. Tese (Doutorado em Educação) - Universidade Federal do Espírito Santo, Vitória, 2014.

SOUZA e SILVA, Jailson. caminhada de estudantes da maré para a universidade. Tese (Doutorado em Educação). Departamento de Educação, Pontifícia Universidade Católica do Rio de Janeiro, Rio de Janeiro, 1999.

TEIXEIRA, Moema de Poli. Identidade e trajetórias de ascensão social no Rio de Janeiro. Rio de Janeiro: Pallas, 2003.

Submissão em: 16/04/2016.

Aprovação em: 18/05/2016. 
